\title{
Tension pneumocephalus and rhinorrhea related to chronic sinusitis
}

\author{
Pneumoencéfalo hipertensivo e rinorreia relacionados à sinusite crônica \\ Victor de Almeida Kosac', André PC Matta², Frederico M Prado', Osvaldo JM Nascimento², Gabriela DJ Matta, \\ Tereza CS dos Santos ${ }^{4}$
}

A 42-year-old woman presented with a sudden-onset severe headache associated with vomiting and a persistent aqueous rhinorrhea. She had an allergic chronic sinusitis. There was no history of head trauma. Neurologic exam disclosed papilledema. The computed tomography (CT) scan showed opacification of the left sphenoid sinus and pneumocephalus extending

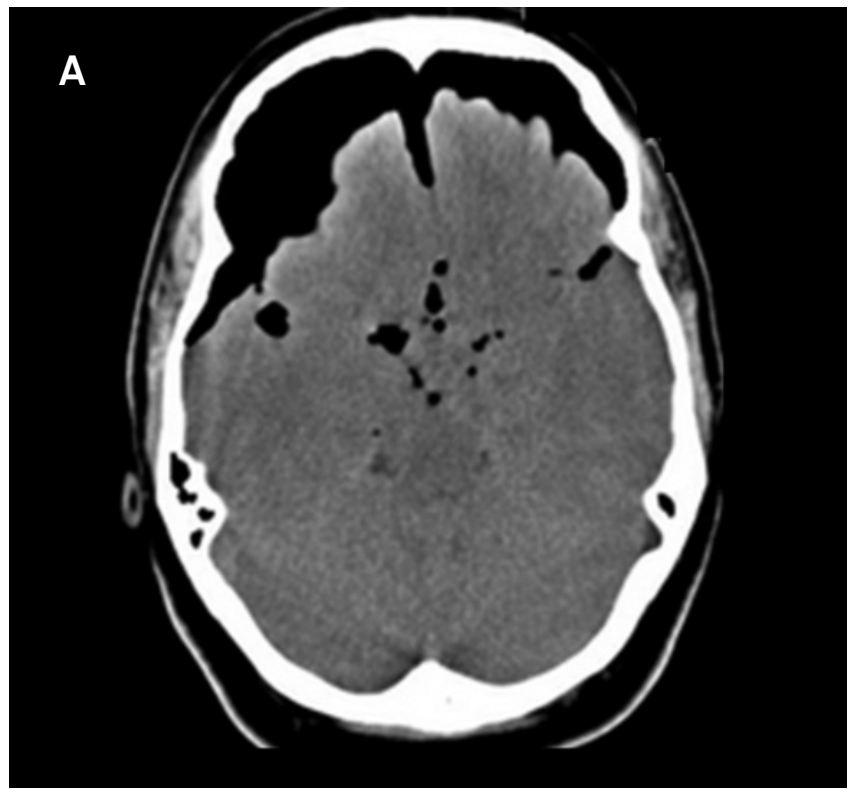

Fig 1. Computed tomography shows huge pneumocephalus extending from right temporal fossa and bilateral frontal region until convexity compressing supratentorial ventricular system. from frontal region until convexity, compressing the supratentorial ventricular system (Fig 1). The cerebrospinal fluid (CSF) fistula was found in the left pterygoid process (Fig 2). Air probably came through the dural defect, and may have followed the CSF flow circuit. The physiopathology can be explained by bone defect, absence of nasal mucosa, and minor traumas ${ }^{1,2}$.

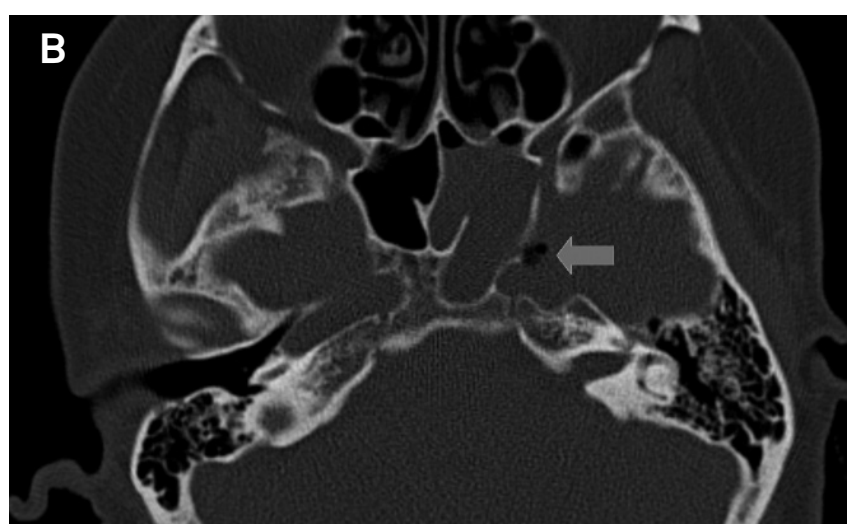

Fig 2. High resolution computed tomography shows opacification of the left sphenoid sinus and bone defect of the left pterygoid process (arrow) permitting the airflow through the fistula.

\section{References}

1. Lefranc M, Peltier J, Demuynkc F, et al. Tension pneumocephalus and rhinorrhea revealing spontaneous cerebrospinal fluid fistula of the anterior cranial base. Neurochirurgie 2009;55:340-344.
2. Webber-Jones JE. Tension pneumocephalus. J Neurosci Nurs 2005;37: 272-276.

\footnotetext{
${ }^{1}$ Medical residents of Neurology, Department of Neurology, Federal Fluminense University, Niterói RJ, Brazil; ${ }^{2} \mathrm{MD}$, PhD, Professor of Neurology, Department of Neurology, Federal Fluminense University, Niterói RJ, Brazil;

${ }^{3}$ Ophthalmologist, Post-graduating program in Neurology and Neuroscience, Federal Fluminense University, Niterói RJ, Brazil; 4Radiologist at Antonio Pedro Hospital, Federal Fluminense University, Niterói RJ, Brazil.

Correspondence: Victor de Almeida Kosac; Rua Doutor Paulo César 25 / apto. 1.608; 24240-000 Niterói RJ - Brasil; E-mail:victorkosac@yahoo.com.br Conflict of interest: There is no conflict of interest to declare.

Received 18 March 2012; Received in final form 26 November 2012; Accepted 03 December 2012.
} 